\title{
Five lessons from a year of virtual patient partnerships
}

\author{
— Cite as: CMAJ 2021 July 26;193:E1145-6. doi: 10.1503/cmaj.1095953
}

Posted on cmajnews.com on July 9, 2021

$\mathbf{T}$ he shift toward online collaboration during the COVID-19 pandemic has removed some barriers to patient partnership in health research and created new ones. Researchers and patients shared lessons from this transition in a recent grand rounds presentation hosted by the George \& Fay Yee Centre for Healthcare Innovation (CHI) in Manitoba.

\section{Tackle tech issues early and often} Anna Chudyk, a postdoctoral fellow with the College of Nursing at the University of Manitoba, said meeting virtually made it possible to include a "wider range of perspectives" in her research.

"Online engagement also supported us in breaking up [a workshop with cardiac surgery patients and their caregivers] over multiple days, both to reduce participant fatigue as well as to give individuals time to reflect," she said.

However, Chudyk said these activities took "a lot more time to plan" than usual due to technological challenges. She recommended having a person designated to troubleshoot tech issues as they arise. According to Chudyk, "it works best not only to talk about these needs when you make initial contact... but also through a follow-up tech needs assessment survey."

Access to computers, cellphones and a reliable Internet connection is essential to virtual patient engagement, and shouldn't be taken for granted, said Angela Tessier of CHI's Patient and Public Engagement Collaborative Partnership. Researchers must also consider patients' comfort with technology and not assume they are familiar with online etiquette, she said. For example, facilitators may need to explain before each meeting "how to raise your hand, how to mute, and how to use chat features."

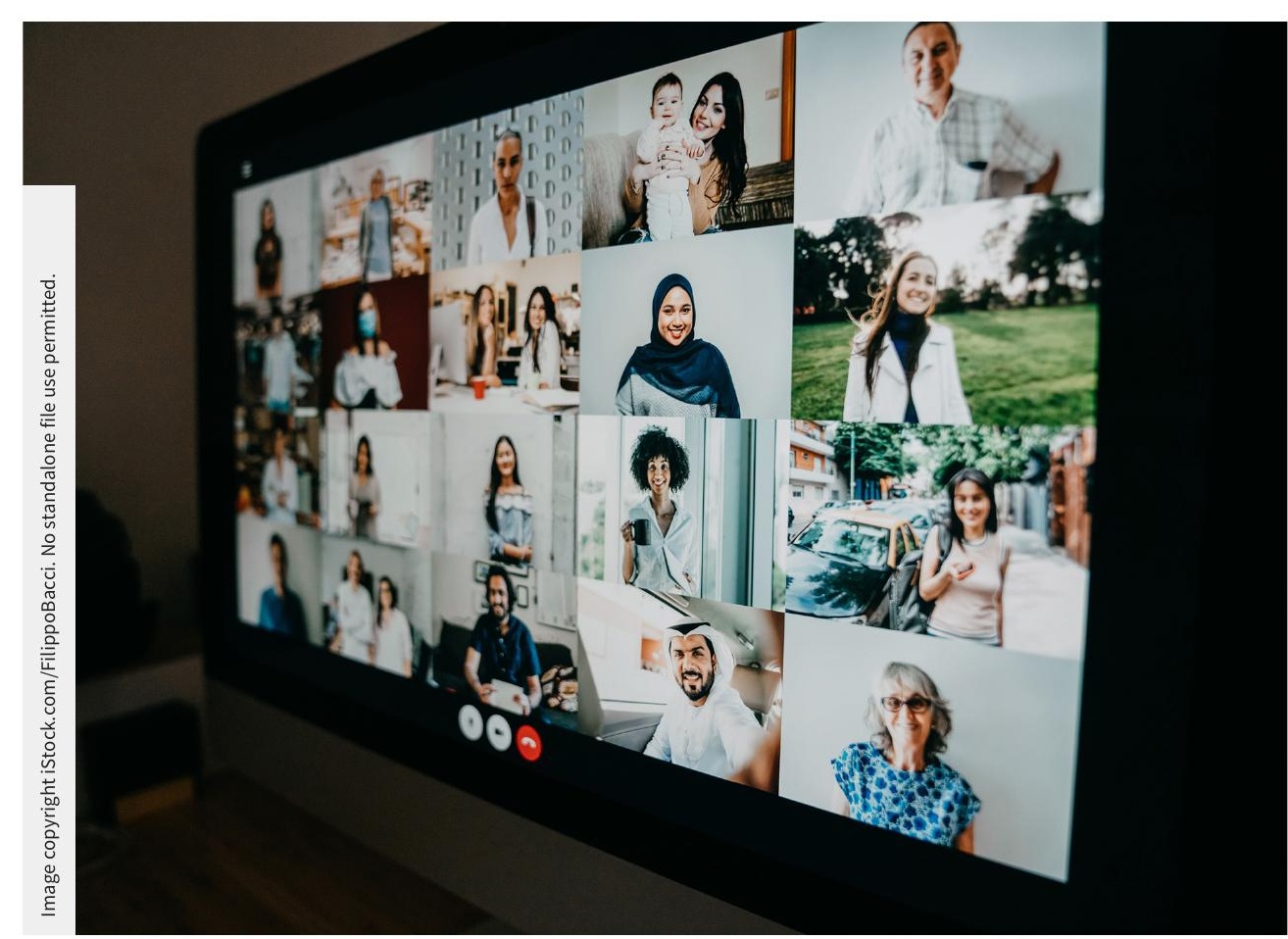

Moving patient partnerships online brought logistical challenges but also greater flexibility.

\section{Think beyond the nine-to-five}

Other hurdles to online collaboration may require researchers to meet patients on their own terms and schedules.

Many patients may have limited bandwidth for partnerships during the pandemic, Tessier said. "While people may want to be patient partners, life may just be too difficult or too stressful at this moment."

Privacy is another critical element to consider. Some patients may not want other people to see where they live "for fear of judgment," Tessier explained. Others may not want their families or roommates to know they're involved in research.

In such cases, flexibility is key. "We tend to work within a nine-to-five bubble, and that may not always work for patients,"
Tessier said. "I have taught math at midnight because that's what met the needs of my students; in the same way, it may be necessary to meet in the evenings or maybe even on weekends to help accommodate the needs of patients."

\section{Comfort makes for confidence}

Moving patient partnerships online has brought major benefits for people with chronic pain and other disabilities, said Paula Orecklin, a patient advisor to several organizations including $\mathrm{CHI}$, Winnipeg Regional Health Authority, and the Canadian Agency for Drugs and Technologies in Health.

Orecklin, who lives with complex regional pain syndrome, used to depend 
on other people for rides to meetings and often arrived early "just so the pain would go down enough that I could participate."

Now that it's possible to take meetings while resting at home, Orecklin said she has been able to "think, participate and generally enjoy things more."

"My as-needed pain medication usage is down significantly," she said. "I feel a lot more prepared and likely to put myself forward to new organizations."

Orecklin also noted that collaborating from the comfort of home can change the power dynamics of patient partnerships. "The entire energy is very different," she said. "You don't enter into the intimidating, big, busy hospital or the halls of academia."

\section{Connection requires focus}

Carrie Costello, a patient engagement coordinator with the Children's Hospital Research Institute of Manitoba, initially worried that young patients and their families would drop out of engagement activities during the pandemic. Surprisingly, "people actually came on a more regular basis," she said.

According to Costello, distractions during meetings posed a bigger challenge than attendance. "I see it in myself and other people," she said. In online meetings, "my mind starts to wander and then I might check my phone and look at an email. Before I know it, I realize that I haven't heard the last five minutes because I was answering that email."

To make online meetings more interactive, Costello recommended switching between slideshows and face-to-face view, asking questions, and using tools like Google's Jamboard or Zoom's Whiteboard.

Trust is critical to patient partnerships, but it can be difficult to build without the casual connections people make "getting coffee or having a conversation about your dog or kids," Costello says. "It's that connection that makes a team."

One youth advisory committee has tackled this challenge by extending their meetings by half an hour to play online games together. Another group takes time at the beginning of meetings to share one good thing and one bad thing going on in their lives.

\section{Share the spotlight}

Costello also asks permission to call on people randomly during meetings to make sure everyone has a chance to participate. "In a virtual world, it's very hard to have natural conversations because we can't talk over each other; it feels like interrupting," she said.

Costello's 13-year-old daughter, Emma Felices-Costello, has been a partner and participant in health research during the pandemic. She said miscommunication is a major challenge young people face when collaborating virtually with adults.

"We get bored listening to the other speeches because we often can't understand half of what they're saying," FelicesCostello explained. "You can't read the room like you would in person."

Sometimes, this has led to uncomfortable situations, she said. "But because it is online, I feel that I can't say so, especially in the presence of adults."

For example, Felices-Costello noted that young people often have to cut their comments short if adults speak first in online discussions and go over time. She urged researchers to give young people more time to speak at the beginning of meetings rather than leaving them to the end. "Make sure we're not in the shadows of adults," she said.

\section{Diana Duong, CMAJ}

Content licence: This is an Open Access article distributed in accordance with the terms of the Creative Commons Attribution (CC BY-NC-ND 4.0) licence, which permits use, distribution and reproduction in any medium, provided that the original publication is properly cited, the use is noncommercial (i.e., research or educational use), and no modifications or adaptations are made. See: https://creativecommons.org/ licenses/by-nc-nd/4.0/ 